- cirrus, cumulus, stratus, nimbus and cumulo-nimbus, cirro-cumulus and cumulo-cirrus, cirro-stratus and stratocirrus, together with strato-cumulus-comprise all the important kinds of clouds; and there are really only five distinct types of structure-cirrus, stratus, cumulus, nimbus, and cirro-cumulus. Prof. Hildebrandsson and myself consider that the ten words above mentioned, compounded out of only four Latin words, are practically sufficient for all ordinary purposes.

Specialists in clouds will of course want more minute varieties, such as different names for some of the kinds of cirrus, and for the low broken clouds, such as scud, wrack, \&c. There are also a whole class of pendulous clouds, such as festooned stratus, pocky cloud, or mammato-cumulus; and the long black wreaths of cloud in front of certain types of thunderstorm, but these are all very local, and also very short-lived, so that they need only be mentioned here.

So far for the mere external forms of clouds as they would strike a savage or an artist ; but to the meteorologist there is a philosophy behind them. In England some forms presage wind and rain, others indicate the advent of fine weather; while recently it has been shown that different kinds of clouds are developed in different parts of cyclones and anticyclones. For instance, cirrostratus forms in front, cumulus in rear, of a cyclone; while fleecy cirro cumulus is very characteristic of the western side of the anticyclones.

But then we are met by the apparent paradox that precisely the same forms of cloud are found on the equator where neither cyclone nor anticyclone was ever developed. Moreover, the same cloud does not prognosticate the same weather all over the world, and even in the same country the same cloud may indicate either gnod or bad weather according to the circumstances under which it is developed. For instance, cumulus in England is sometimes the associate of a fine day, other times the forerunner of a shower.

The clue to the whole puzzle lies in the fact that the same form of cloud can be produced under totally different circumstances. Vapour-Iaden air can only condense into cloud, and then be drawn out or rolled about between different currents in a very limited number of ways, and hence the small number of really distinct varieties of cloud structure.

Let us take the case of cumulus in detail as an example of general principles. Cumulus is always the condensed capital of an ascensional column of air, but the source of the uptake need not always be the same. For instance, air may rise either (I) from ordinary evaporation on a fine day ; (2) from the uptake of a cyclonic vortex; (3) from the collision between two opposite currents.

The first-evaporation-is the source of fine-weather cumulus in England and all over the world; while the uptake of a cyclone is the cause of rainy cumulus wherever such eddies are formed. The rainy cumulus of the equator is the product of squalls and thunderstorms whose nature at present is unknown in most cases; but one very common cause is the collision between the land and sea breezes of the tropics. The two opposing currents meet, one is forced upwards, and then mountainous cumulus is the result. The cumulo-nimbus in Fig. 3 is over a thunderstorm in Borneo, due to the collision of the land and sea breezes.

All, therefore, that we can say for certain when we see a cumulus cloud is that an ascensional current of air has risen to the level of condensation. What future weather the cloud prognosticates depends on circumstances, and must be judged by our experience and knowledge of the climate in which we may happen to be. Clouds always tell a true story, but one which is hard to read; and the language of England is not the language of Borneo. The form alone only shows that a certain form of condens- ation is taking place; the true import must be judged by the surroundings, just as the sense of many words can only be judged by the context.

\section{RALPH ABERCROMBY.}

\section{FIFTH ANNUAL REPORT OF THE FISHERY BOARD FOR SCOTLAND.}

THE Report for 1886 contains so much of general interest that it deserves the attention of many who look upon a Blue-book as the driest of reading, only attractive to those whom it may immediately concern. It is desirable that the scope and practical aims of the Board should be more generally known, and the public should appreciate the excellent work done by it, instead of regarding this as the mere outcome of scientific leanings to certain lines of investigation. The fisheries of Scotland continue to be very productive, and nothing is more striking about them than the great and increasing yield of the herring fishery. Though this increase and the low price at which the herrings have been sold have proved a great boon to the community, especially to the poorer classes, it is deeply to be regretted that the crews sustained very heavy losses from the glutting of the market consequent on the large takes and low prices. A striking feature of the summer herring fishery of 1885 was that many in-shore grounds where herrings had been found in great abundance in previous years but which had been recently all but deserted were restored to their former fertility. This was even more marked in the season of I 886, as all along the east coast from Montrose to the Pentland Firth there seemed to be one immense unbroken shoal of herrings, lying from one to ten miles off land. At no former period in the history of this fishery were the catches so heavy. The winter herring fishery on the east coast was the most productive ever known, yielding a total catch of $128,44 \mathrm{I}$ crans. The gross total value of the sea and salmon fisheries of Scotland for 1886 was $£ 2,550,778$ 8s. $3 d$.

During the past year the scientific work consisted chiefly in carrying on the trawling experiments required by the recent Act of Parliament (Sea Fisheries (Scotland) Amendment Act, 1885), but in addition investigations were made as to the development, artificial hatching, structure, and habits of the more important useful fishes. An important part of the inquiry as to the influence of trawling consisted in arranging to obtain statistics showing the quantities of fish landed from the restricted areas, and the conditions under which they were captured-an extremely difficult matter to arrange.

The Board's marine station at St. Andrews has again been under the direction of Prof. McIntosh, whose Report shows that important work on the life-histories and development of the food-fishes has been done at this station. by him and Mr. E. E. Prince, by Dr. Scharff on the intra-ovarian eggs of food-fishes, and by Mr. Wilson on the development of the common mussel. The memoir first mentioned, viz. that on the development and life-histories of the food-fishes, is now ready for publication, and is illustrated by thirty-one quarto plates. Its size and the nature of the illustrations of course render it unsuitable for a Parliamentary Blue-book.

The "Report on the Trawling Experiments on the East Coast, Part I. Preliminary," by Prof. Ewart and Sir J. Ramsay Gibson-Maitland, gives the results of an important item in last year's work. The Act already referred to having empowered the Scotch Fishery Board to frame by-laws for the better regulation of sea-fishing, and one such law having been framed, passed, and confirmed, it was necessary to make arrangements to discover, if possible, what influence the prohibition of trawling under the by-law would have in leading to 
an increase of fish in the protected waters. At the outset it was evident that it would be necessary to make systematic observations on the various areas by trawling along the same lines, and as nearly as possible under the same conditions, as the ordinary steam trawlers; and further, that it would be equally necessary to obtain as far as possible a record of the fish captured day by day from the various grounds in the Firth of Forth, St. Andrews and Aberdeen Bays.

Representations having been made that a small steamvessel properly fitted out was indispensable, and a sum for the buying and maintenance of such a vessel having been granted, the Garland, an iron fishing yacht, was purchased and duly equipped. She was provided with a steam winch, trawling gear, dredges, \&c., and later it was found desirable to add a small bridge to admit of a better "look-out" being kept when at work during the night in the vicinity of small fishing-boats, often imperfectly protected by lights. The beam of the trawl provided is twenty-five feet in length, i.e. about half the length of those used by the ordinary steam trawlers. This size was selected partly to suit the weight of the ship, and partly to cause as little disturbance as possible to the fishing-grounds when under periodical inspection. Special forms were prepared to admit of a complete record being kept of the fish taken by the trawl, dredge, and tow-net, and of the temperature, state of the weather, \&c. The Garland was supplied with charts, showing the extent and direction in which the trawl was to be carried in working over the various trawling stations, and with several books of reference, bottles, tanks, \&c., for the preservation of spawn, young fish, crustacea, and other objects which required to be afterwards examined or identified. Recently a complete set of thermometers and other instruments for making physical obşervations have been provided, and the necessary instructions given for their use.

In the present Report it is pointed out that the Firth of Forth is well adapted either as a feeding-ground or a nursery for the most important of our focd-fishes and also for shell-fish. As a matter of fact, there is not, it is stated, on the east coast of England or anywhere else on the coast of Scotland, a stretch of water with so many natural advantages from the fishermen's point of view as the Firth of Forth. The fresh water carries with it food for mussels and other shell-fish. The sea brings in food for herring and other round fish. The water varies considerably in depth and salinity, and the bottom at one part consists of sand or mud, at another of gravel or shingle, and at another of rocks, sometimes bare, sometimes covered with sea-weed, and the temperature throughout the year is fairly constant, there never being great heat in summer or very great cold in winter. The physical conditions of St. Andrews Bay are entirely unlike those of the Forth, and this being the case the fauna may naturally be expected to differ considerably. There has not been time to prepare a complete account of the fauna of St. Andrews Bay during the different months of the year, but it is hoped that with the help of Prof. McIntosh a first list will be ready for the next Report. It is, bowever, known already that the rocky ground on the south shore is rich in mollusks, crustacea, marine worms, cœlenterates, \&c. ; and that starfish and other echinoderms, edible, swimming, and hermit crabs and other crustacea are scattered in abundance over the sandy bottom of the bay, and especially that mussels abound near the mouth of the Eden. Further, swimming or pelagic forms (including at certain seasons of the year schools of young fish, crustacea, and mollusks) teem in the surface and deeper waters. As is to be expected from the nature of the bottom, flat fish far out-number round fish all over the bay. The flat fish are chiefly represented by several kinds of dabs, by plaice, flounders, skate, and brill, and at times turbot; and in addition the bay is visited by had- dock, whiting, cod, and other round fish. Aberdeen Bay corresponds in some respects with St. Andrews Bay, but the closed area includes not the bay proper so much as a narrow portion of the territorial waters (some eighteen miles in length) which extends from Girdle Ness to the Cruden Scars. This area, very narrow at certain points, never reaches a width of three miles. The Dee, Don, and Ythan flow into the bay, but the fresh water flows over the salt without mingling with it as in the Forth to form a true estuary. The bottom consists chiefly of sand, but towards the north and south sand gives place to rock. The fauna resembles that found at $\mathrm{St}$. Andrews, but although flat fish are relatively plentiful, whiting are far more abundant. It is to be observed that, in comparing the prominent features of the three districts investigated, the Firth of Forth is characterized by an abundance of haddocks, St. Andrews Bay by the predominance of flat fish, and Aberdeen Bay by the large number of gurnards and whitings. As regards the practical working of the by law, it is only necessary to add that although only a year has elapsed since it was passed, providing for a limited form of protection for the waters referred to, there are already some signs of improvement both in the number and size of the less migratory flat fish, and in the number of young round fish which visit the territorial waters for long or short periods. The fishermen of the Forth and St. Andrews Bay state they are already obtaining better takes of flat fish, and that they believe in a few years the in-shore grounds will have recovered to a considerable extent their former richness.

Prof. Ewart gives an interesting paper on "The Artificial Hatching and Rearing of Sea Fish." The publication last year of "The History of Howietoun" (Sir J. Ramsay Gibson-Maitland) marks an epoch in the history of fishculture. It affords proof that the Salmonidæ at least can be bred and reared in confinement as successfully as any of the smaller domestic animals, and that fish-culture, notwithstanding all the reverses it has suffered through the misplaced zeal and energy of its many would-be advocates, has a great future before it, not only in restocking our own rivers and lakes, but also in peopling the waters of all countries where the conditions are favourable to the development and growth of the Salmonidæ and other valuable food-fishes. Fish-culture at Howietoun has been reduced to a science. Every step in the process, from the impregnation of the eggs to the rearing of the mature fish, has been thoroughly mastered and systematized. So careful have the observations been from first to last, that it is now possible to produce, within certain limits, considerable modifications in the time at which the eggs mature and hatch, and in the rate of growth of both the fry and the older fish; and further, many hybrids have been bred, the genealogy of which is not a little hard without the aid of an ancestral tree to fully comprehend.

The reasons for putting such knowledge acquired to a practical application are that the demand for salmon is greater than formerly, and the nature of the spawninggrounds has been altered. Nature provides for all natural losses, but she does not, and cannot be expected to cope with those created by the necessities of civilization. It is for science to step in and help to solve the problem of supply and demand.

Unlike the higher animals, fish are not protected in the early stages, and the food-fishes even less than others. A very limited acquaintance with the life-history of sea-fish enables one to readily understand that, though the culture of salmon and trout may be highly advantageous, and often all but imperative, it does not follow that this is the case with the herring and cod and their allies. The most sanguine pisciculturist would scarce dare propose to increase the number of the more migratory fish that live in the open sea. It has been suggested that, by hatching 
fish in-shore, local races might be formed; but this is taking for granted that during the process of incubation the fish are brought under some remarkable spell which arrests their strongly inherited instincts, and leads them to settle down for life in the vicinity of their birthplace, instead of roaming about to see the world like their free born cousins. It seems, therefore, too much to expect cod and haddock and other wanderers to remain always about our doors because they happened to see the light under artificial instead of natural conditions. But though fish-hatching may not be able to influence much, if at all, the number of fish in the open sea, and though it may not be able to establish local races or shoals, it may still be of great service. In the first place, it may be the means of introducing fish, which have the migratory instinct fairly well developed, into waters where they practically did not previously exist. For example, by instituting hatcheries in the upper reaches of some of the long fjords in Norway, a large school of haddocks or other round fish might be readily created which might find all the conditions necessary to their existence without wandering into the open sea; and, in fact, the same results might follow the hatching on a large scale of round fish in some of our own firths and bays. Again, as in America, it might be possible to produce shoals of fish, such as the shad, which, by wandering along the coast or living in the estuaries, would be the means of attracting large and more valuable forms to the in-shore grounds; fish, in fact, which would act the part of the herring, but be a more constant source of attraction-remaining in the firths for several months at a time. Lastly, fish-culture may have a great future before it in hatching flat fish, which have the double advantage of being extremely valuable, while they are often very limited in their migrations. The artificial hatching of sea-fish has not yet had time to obtain a firm footing; for the first trustworthy experiments made were those of the German Commissioners (Meyer, Möbius, and others), who hatched numerous herring in 1874 in the Bay of Kiel. As is well known, Norway has a Society for Promoting the Norwegian Fisheries, with branches at the principal fishing centres. In 1882 an experimental station under Captain G. M. Dannevig was started at Flödevig, near Arendal, where millions of sea-fish have been hatched, and a number of cod and herring reared in a pond near the hatching station. The question of hatching sea-fish is under consideration at the present moment at Grimsby. It is proposed to found a hatchery at Cleethorpes to propagate round and flat fish, with a view of replenishing the exhausted in-shore waters of the North Sea. Even should this experiment prove unsuccessful, it will be of importance in furnishing and spreading the technical education and information so much required among those engaged in the fishing industry.

To successfully hatch sea-fish in large numbers, the first and last requisite is an abundant supply of pure sea-water. This necessitates a small sea-pond and a number of large tanks, from which a constant supply of pure filtered water can be readily obtained. In addition to having at command an abundant supply of sea-water, it is, of course, necessary to have the hatching-station in the vicinity of some rich fishing-ground, where plenty ripe fish may be obtained when wanted.

Given plenty pure sea-water and a number of ripe fish, the next desideratum is a hatching apparatus, the form of which must depend on the nature of the eggs to be manipulated. While herring eggs are heavy, and not only fall to the bottom, but adhere to whatever they touch, the eggs of most of the food-fishes are nonadhesive and lighter than sea-water, and hence they float at or near the surface. Prof. Ewart describes and figures a promisingly practical hatching jar for adhesive eggs lately designed and used by himself, also the apparatus used at Arendal for floating exgs, the most suc- cessful hitherto devised. With such apparatus it would be possible, at a very small outlay, to hatch millions of floating food-fish eggs, and thus to restore and maintain the original productiveness of the in-shore fisheries. The conclusion is that we ought to establish hatching stations at one or more centres. One might be for round fish, the other for lobsters and other shell fish. The Firth of Forth and the Cromarty Firth seem admirably adapted for the purpose, one great point being that minute pelagic forms, such as the young fry feed on, are remarkably abundant in both. A hatching station could be provided for about $£$ ioos, and it is hoped the Board may soon obtain a vote for the purpose. The hatching operations at Flödevig, of the report of which Prof. Ewart gives an interesting abstract, shows that many important practical questions have been settled, and the conclusions reached at Howietoun and elsewhere as to the influence of extreme temperatures, sudden changes in the surroundings, and also on the eggs and young spawn on full-grown fish, have been well confirmed.

Mr. Duncan Matthews gives (Part I.) a long paper, excellently done, on "The Structure of the Herring and other Clupeoids," with a series of capital plates ; also Part II. of the "Report as to variety among the Herrings of the Scotch Coast"; notes on "The Fond of the Whiting," and on the "Ova, Fry, and Nest of the Ballan Wrasse." Mr. R. D. Clarkson's paper "On the Nutritive Value and Relative Digestibility of White Fish" is as interesting from the dietetic point of view as $\mathrm{Mr}$. C. E Fryer's suggestions for "The Preparation of Sprats and other Fish as Sardines" is from the economic. Prof. McIntosh reports on the work done last year at the St. Andrews Marine Laboratory. The other scientific investigations include notes on "The Food of Young Gadidæ," and on "The Spawning of the Pike," by Mr. George Brook; on "Entomostraca," by Mr. G. S. Brady; a paper on the "Development of the Common Mussel," by Mr. John Wilson; one on "The Physical Conditions of the Water of the Firth of Forth," by Dr. H. R. Mill ; and a "Further Report on the Examinations of River-waters for Micro-organisms," by Prof. Greenfield and Mr. John Gibson. There are a number of tables and plates which add greatly to the interest and usefulness of the work.

\section{PROFESSOR A. WEISMANN'S THEORY OF POLAR BODIES.}

$\mathrm{NE}$ of the most noticeable features at the recent meeting of the British Association at Manchester was the manner in which naturalists of all nationalities agreed to do honour to Prof. Weismann, who has contributed to theoretic biology in the last few years with as lavish a hand as that with which he formerly enriched the practical side of the science through detailed observation and far-reaching irduction.

Of his later speculations upon the significance of obscure reproductive phenomena, the first ${ }^{1}$ was abridged by Prof. H. N. Moseley (Nature, vol. xxxiii. p. I 54); while perhaps the most important contribution to biological science at the Manchester meeting was an abstract of the newer pamphlet ${ }^{2}$ recently reprinted in this journal (vol. xxxvi. p. 607). The necessary limits of such an abstract precluded any account of the observations which appeared to support Prof. Weismann's views, as also of the details of the process by which, as he supposes, the plasmata are removed in the polar bodies. As neither the original pamphlet nor the still later account of his observations upon parthenogenetic eggs are generally accessible, it has been suggested that some additional points, in expansion of the abstract, should be given in these columns.

$$
\begin{aligned}
& \text { × "Die Continuität des Keimplasma"s," Jena, } x 885 \text {, r22 pages. } \\
& 2 \text { "Die Zahl der Richtuagsköper," Jena, r387, } 75 \text { pages. }
\end{aligned}
$$

